\title{
HUBUNGAN TINGKAT NYERI LUKA OPERASI DENGAN MOBILISASI DINI PADA IBU POST SECTIO CAESAREA DI PAVILYUN MELATI RSUD JOMBANG
}

\section{The Correlation Of Surgical Pain Level With Early Mobilization For Post Sectio Caesarea Mother In The Ward Of Melati Rsud Jombang}

\author{
Anis Satus $S^{1 *)}$, Mamik Ratnawati ${ }^{2)}$, Amanda Dewi Kharisma ${ }^{3)}$ \\ *E-mail: syarifah_anissatus@yahoo.co.id
}

\begin{abstract}
ABSTRAK
Pendahuluan: Nyeri yang dirasakan ibu post SC berasal dari luka yang terdapat di perut. Nyeri merupakan sensasi yang sangat personal yang tidak dapat dibagi dengan orang lain. Rasa nyeri yang masih terasa 2-3 hari setelah SC umumnya membuat ibu enggan menggerakkan badannya, hal inilah yang menyebabkan mobilisasi dini ibu kurang baik.Tujuan penelitian ini adalah mengetahui hubungan tingkat nyeri luka operasi dengan mobilisasi dini pada ibu post SC. Metode: Desain pada penelitian ini menggunakan analitik korelasi dengan pendekatan cross sectional, dilakukan pada tanggal 17 s.d 27 April 2018, bertempat di Pavilyun Melati RSUD Jombang. Populasi adalah semua ibu post SC di Pavilyun Melati RSUD Jombang rata-rata setiap bulan sebanyak 68 responden, besar sampel adalah 34 responden. Teknik sampling menggunakan Purposive Sampling. Variabel independen adalah tingkat nyeri luka operasi, sedangkan variabel dependen adalah mobilisasi dini. Data analisis menggunakan uji statistik Spearman Rank. Hasil: Hasil penelitian didapatkan sebagian besar responden dengan nyeri sedang mempunyai mobilisasi dini cukup yaitu sebanyak 13 orang (72,2\%). Hasil uji statistik didapatkan $\rho=0,002<\alpha=0,05$ dan koefisien korelasi=0,515. Artinya, ada hubungan "sedang" antara variabel independen dengan variabel dependen sehingga H1 diterima dan H0 ditolak. Kesimpulan: Tindakan yang perlu dilakukan untuk ibu post SC untuk mengurangi nyeri yaitu dengan memberikan analgesik dan mengajarkan teknik relaksasi dan distraksi. Selain itu ibu juga harus diberi informasi dan arahan untuk melakukan mobilisasi dinI. Dengan adanya informasi yang memadai tentang pentingnya mobilisasi dini dan pengawasan dari petugas kesehatan diharapkan dapat meningkatkan motivasi ibu untuk melakukan mobilisasi dini.
\end{abstract}

Kata Kunci: Nyeri, Mobilisasi Dini, Sectio Caesarea

\begin{abstract}
Introduction: The pain which is felt by the post SC mother comes from the wound in the abdomen. Pain is a very personal sensation which can not be shared with other people. Pain which is still felt 2-3 days after SC generally makes the mother reluctant to move her body, this case which causes early mobilization of mother is not good. This research aimed to know the correlation of surgery pain level with early mobilization for post SC mother. Method: This design of research used analytic correlation with cross sectional approach, which was conducted from April $17^{\text {th }}$ to April $27^{\text {th }} 2018$, which was located in the ward of Melati RSUD Jombang. The population was all post SC mothers in the ward of Melati RSUD Jombang each month average was 68 respondents, the l of samples was 34 respondents. Sampling technique used Purposive Sampling. The independent variable was surgical pain level, whereas the dependent variable was early mobilization. Data analysis used test Spearman Rank. Result: The result of research was gotten from most respondents with moderate pain have early enough mobilization as many as 13 people (72,2\%). Statistical test result was obtained that $\rho=0.002<\alpha=0.05$ and correlation coefficient $=0,515$. It meant that there was a "moderate" correlation between independent variable with the dependent variable so that $H 1$ was accepted and $H O$ was rejected. Conclusion: The action which needs for post-SC mothers to reduce pain, namely by giving

analgesics and teaching relaxation and distraction techniques. Besides, the mother must also be given information and direction to do early mobilization. With adequate information on the importance of early mobilization and supervision from health workers are expected to be able to increase the motivation of mothers to do early mobilization.
\end{abstract}

Keywords: Pain, Early Mobilization, Sectio Caesarea

\section{PENDAHULUAN}

Bedah sectio caesarea (SC) merupakan tindakan pembedahan guna melahirkanjanin lewat insisi pada dinding abdomen, sehingga janin dilahirkan melalui dinding perut dan dinding rahim agar anak lahir dengan keadaan utuh dan sehat (Harnawatiaj, 2008). Nyeri yang 
dirasakan ibu post partum berasal dari luka yang terdapat di perut. Nyeri sangat tidak meneyenangkan dan merupakan sensasi yang sangat personal yang tidak dapat dibagi dengan orang lain. Rasa nyeri yang masih terasa 2-3 hari setelah SC umumnya membuat ibu enggan menggerakkan badannya, hal inilah yang menyebabkan mobilisasi dini ibu kurang baik. Kebanyakan ibu post SC tidak melakukan mobilisasi dini dengan alasan nyeri pada luka jahitan (Bobak, 2005).

Menurut WHO, standar rata rata SC di sebuah negara adalah sekitar $5-15 \%$ (WHO, 2015). Hasil RISKESDAS Tahun 2013 menunjukkan kelahiran dengan bedah SC di Indonesia sebesar 9,8\% dengan proporsi tertinggi di DKI Jakarta $(19,9 \%)$ dan terendah di Sulawesi Tenggara (3,3\%) (RISKESDAS, 2013). Berdasarkan data dari RSUD Jombang pada tahun 2016 jumlah persalinan SC sebanyak 804 kasus dan pada tahun 2017 meningkat menjadi 974 kasus (RSUD Jombang, 2018). Data bulan Januari sampai dengan April 2017 di Pavilyun Melati RSUD Jombang dari 204 orang ibu post SC, yang melakukan mobilisasi dini sebanyak 135 orang sedangkan 69 orang lainnya tidak melakukan mobilisasi dini karena alasan nyeri post SC (Rana, 2017). Berdasarkan penelitian Wati (2015), tentang hubungan nyeri luka operasi dengan mobilisasi dini pada ibu post SC didapatkan hasil bahwa dari 46 responden hampir setengahnya $(43,5 \%)$ nyeri berat terkontrol, sedangkan sebagian besar $(69,6 \%)$ mobilisasi yang dilakukan cukup (Wati, 2015).

Pembedahan SC merupakan tindakan insisi pada dinding abdomen yang menyebabkan terputusnya kontinuitas jaringan, pembuluh darah, dan saraf saraf di sekitar daerah insisi. Hal ini akan merangsang pengeluaran bahan-bahan yang dapat menstimulus reseptor nyeri seperti serotonin, histamin, ion kalium, bradikinin, prostaglandin, dan substansi $\mathrm{P}$ yang mengakibatkan adanya respon nyeri (Kozier, 2010). Nyeri juga dapat disebabkan oleh stimulus mekanik seperti pembengkakan jaringan yang menekan pada reseptor nyeri (Taylor, dkk, 1997). Ketika ibu mengalami nyeri ibu akan takut untuk melakukan mobilisasi dini.
Tingginya kepercayaan orang terhadap budaya jika sering bergerak setelah melahirkan maka benang jahitannya akan putus dan akan lebih sakit jika melakukan mobilisasi dini, sehingga ibu takut untuk melakukan mobilisasi dini (Chapman, 2006). Mobilisasi dini post SC sangat penting untuk dilakukan, sebab jika tidak dilakukan akan memberi dampak diantaranya terjadinya peningkatan suhu, perdarahan abnormal, thrombosis, involusi yang tidak baik, aliran darah tersumbat, peningkatan intensitas nyeri (Suryani, 2010).

Tindakan yang perlu dilakukan untuk ibu post partum dengan SC untuk mengurangi nyeri yaitu dengan mengajarkan teknik relaksasi dan distraksi. Selain itu ibu juga harus diberi informasi dan arahan untuk melakukan mobilisasi dini post SC. Dengan adanya informasi yang memadai tentang pentingnya mobilisasi dini dan pengawasan dari petugas kesehatan terhadap mobilisasi dini diharapkan dapat meningkatkan motivasi ibu untuk melakukan mobilisasi dini (Andayani, 2017; Chapman, 2006). Mobilisasi aktif akan mempercepat penyembuhan luka operasi, luka sembuh akan membuat ibu nyaman menyusui dan memungkinkan untuk merawat bayinya secara mandiri.

Berdasarkan uraian diatas peneliti tertarik untuk meneliti tentang hubungan tingkat nyeri luka operasi dengan mobilisasi dini pada ibu post Sectio Caesarea di Pavilyun Melati RSUD Jombang

\section{METODE}

Penelitian ini dilakukan di Pavilyun Melati RSUD Jombang pada tanggal 18 s.d. 27 April 2018. Desain penelitian yang digunakan adalah analitik korelasional dengan pendekatan cross sectional. Variabel independen adalah tingkat nyeri luka operasi, sedangkan variabel dependen adalah mobilisasi dini. Populasi dalam penelitian ini adalah semua ibu post SC di Pavilyun Melati RSUD Jombang sebanyak 68 orang, kemudian besar sampel 34 orang yang dipilih dengan menggunakan teknik Purposive Sampling, yaitu pemilihan sampel dengan cara 
mengambil sampel sesuai kriteria yang telah kita tetapkan.

Instrumen yang digunakan untuk mengukur tingkat nyeri luka operasi dan mobilisasi dini adalah kuesioner yang dibuat oleh peneliti dan sudah melewati tahap uji validitas dan reliabilitas. Pengolahan dan analisis data dilakukan dengan menggunakan program komputer. Dilakukan perhitungan untuk mengetahui hubungan tingkat nyeri luka operasi dengan mobilisasi dini dengan menggunakan uji statistik Spearman Rank.

\section{HASIL}

Penyajian data yang ditampilkan meliputi data umum dan data khusus. Data umum berisi tentang gambaran tempat penelitian, usia responden, tingkat pendidikan, paritas dan riwayat SC. Data khusus berisi tentang tingkat nyeri luka operasi dan mobilisasi dini pada ibu post SC di Pavilyun Melati RSUD Jombang.

Tabel 1 Tabulasi Silang Antara Tingkat Nyeri Luka Operasi dengan Usia di Pavilyun Melati RSUD Jombang.

\begin{tabular}{|c|c|c|c|c|c|c|}
\hline \multirow{3}{*}{ Usia } & \multicolumn{5}{|c|}{ Nyeri } & \multirow[b]{2}{*}{ Total } \\
\hline & $\begin{array}{l}\text { Tidak } \\
\text { Nyeri }\end{array}$ & Ringan & Sedang & $\begin{array}{c}\text { Berat } \\
\text { terkontrol }\end{array}$ & $\begin{array}{c}\text { Berat } \\
\text { tidak } \\
\text { terkontrol }\end{array}$ & \\
\hline & $f(\%)$ & f(\%) & f(\%) & $\mathrm{f}(\%)$ & $\mathrm{f}(\%)$ & $\mathrm{F}(\%)$ \\
\hline $20-$ & 0 & 2 & 2 & 0 & 0 & 4 \\
\hline 25 & (0) & (50) & (50) & $(0)$ & (0) & (100) \\
\hline $26-$ & 0 & 6 & 6 & 0 & 0 & 12 \\
\hline 30 & (0) & $(50)$ & (50) & $(0)$ & (0) & (100) \\
\hline $31-$ & 0 & 7 & 10 & 1 & 0 & 18 \\
\hline 35 & (0) & $(38,9)$ & $(55,6)$ & $(5,6)$ & $(0)$ & (100) \\
\hline
\end{tabular}

Sumber: Data Primer, 2018.

Tabel 2 Tabulasi Silang Antara Tingkat Nyeri Luka Operasi dengan Paritas di Pavilyun Melati RSUD Jombang.

\begin{tabular}{|c|c|c|c|c|c|c|}
\hline \multirow{3}{*}{ Paritas } & \multicolumn{4}{|c|}{ Nyeri } & & \multirow[b]{2}{*}{ Total } \\
\hline & $\begin{array}{l}\text { Tidak } \\
\text { Nyeri }\end{array}$ & Ringan & Sedang & $\begin{array}{c}\text { Berat } \\
\text { terkontrol }\end{array}$ & $\begin{array}{l}\text { Berat } \\
\text { tidak } \\
\text { terkontrol }\end{array}$ & \\
\hline & $\mathrm{f}(\%)$ & $\mathrm{f}(\%)$ & $\mathrm{f}(\%)$ & $f(\%)$ & $f(\%)$ & $\begin{array}{l}\mathrm{F} \\
(\%)\end{array}$ \\
\hline & 0 & 5 & 4 & 0 & 0 & 9 \\
\hline Primıpara & (0) & $(55,6)$ & $(44,4)$ & (0) & (0) & (100) \\
\hline Multipara & (0) & (40) & $14(56)$ & $1(4)$ & (0) & (100) \\
\hline
\end{tabular}

Sumber: Data Primer, 2018. 
Tabel 3 Tabulasi Silang Antara Mobilisasi Dini dengan Pendidikan di Pavilyun Melati RSUD Jombang.

\begin{tabular}{|c|c|c|c|c|c|c|}
\hline \multirow{3}{*}{ Pendidikan } & \multicolumn{5}{|c|}{ Mobilisasi Dini } & \multirow[b]{2}{*}{ Total } \\
\hline & $\begin{array}{c}\text { Sgt } \\
\text { Baik }\end{array}$ & Baik & Cukup & Kurang & $\begin{array}{c}\text { Sgt } \\
\text { Kurang }\end{array}$ & \\
\hline & $\mathrm{f}(\%)$ & $f(\%)$ & $\mathrm{f}(\%)$ & $\mathrm{f}(\%)$ & $\mathrm{f}(\%)$ & $\mathrm{F}(\%)$ \\
\hline \multirow{3}{*}{ Dasar } & 0 & 2 & 6 & 0 & 1 & 9 \\
\hline & (0) & $(22,2)$ & $(66,7)$ & (0) & $(11,1)$ & (100) \\
\hline & 1 & 8 & 6 & 2 & 0 & 17 \\
\hline \multirow[t]{2}{*}{ Menegah } & $(5,9)$ & $(47,1)$ & $(35,3)$ & $(11,8)$ & (0) & (100) \\
\hline & 0 & 4 & 3 & 1 & 0 & 8 \\
\hline Atas & $(0)$ & $(50)$ & $(37,5)$ & $(12,5)$ & (0) & (100) \\
\hline
\end{tabular}

Sumber: Data Primer, 2018.

Tabel 4 Tabulasi Silang Antara Mobilisasi Dini dengan Riwayat SC di Pavilyun Melati RSUD Jombang.

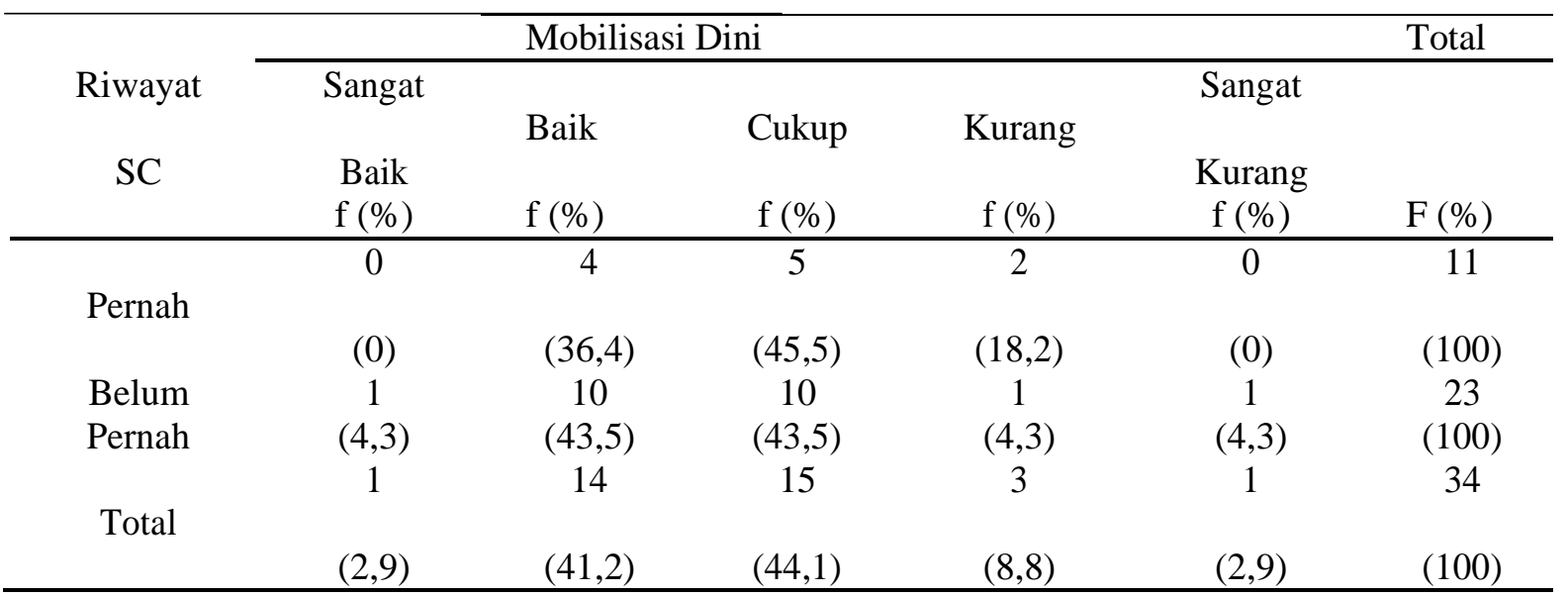

Sumber: Data Primer, 2018.

Tabel 5 Tabulasi Silang Hubungan Tingkat Nyeri Luka Operasi dengan Mobilisasi Dini pada Ibu Post Sectio Caesarea di Pavilyun Melati RSUD Jombang

\begin{tabular}{|c|c|c|c|c|c|c|}
\hline \multirow{3}{*}{ Nyeri } & \multicolumn{4}{|c|}{ Mobilisasi Dini } & \multirow[b]{2}{*}{$\begin{array}{l}\text { Sangat } \\
\text { Kurang }\end{array}$} & \multirow[b]{2}{*}{ Total } \\
\hline & $\begin{array}{c}\text { Sangat } \\
\text { Baik }\end{array}$ & Baik & Cukup & Kurang & & \\
\hline & $\%$ & $\%$ & $\%$ & $\%$ & $\%$ & $\%$ \\
\hline & 1 & 11 & 1 & 1 & 1 & 15 \\
\hline \multirow[t]{2}{*}{ Ringan } & $(6,7)$ & $(73,3)$ & $(6,7)$ & $(6,7)$ & $(6,7)$ & (100) \\
\hline & 0 & 3 & 13 & 2 & 0 & 18 \\
\hline Sedang & (0) & $(16,7)$ & $(72,2)$ & $(11,1)$ & (0) & (100) \\
\hline $\begin{array}{l}\text { Berat } \\
\text { terkontrol }\end{array}$ & $\begin{array}{c}0 \\
(0)\end{array}$ & $\begin{array}{c}0 \\
(0)\end{array}$ & $\begin{array}{c}1 \\
(100)\end{array}$ & $\begin{array}{c}0 \\
(0)\end{array}$ & $\begin{array}{c}0 \\
(0)\end{array}$ & $\begin{array}{c}1 \\
(100)\end{array}$ \\
\hline
\end{tabular}

Sumber: Data Primer, 2018. 
PEMBAHASAN

\section{Tingkat Nyeri Luka Operasi Pada Ibu \\ Post Sc Di \\ Pavilyun Melati Rsud Jombang}

Hasil penelitian menunjukkan bahwa sebagian besar $(52,9 \%)$ responden memiliki tingkat nyeri sedang, yaitu sebanyak 18 orang. Hal ini mungkin dipengaruhi oleh beberapa faktor, antara lain yang tercantum dalam penelitian ini adalah faktor usia dan paritas.

Arthur C. Curton (1983) dalam Andarmoyo (2013) mengatakan bahwa nyeri merupakan suatu mekanisme proteksi tubuh, timbul ketika jaringan sedang rusak, dan menyebabkan individu tersebut bereaksi menghilangkan rasa nyeri. Melzack \& Wall (1988) dalam Andarmoyo(2013) mengatakan nyeri adalah pengalaman pribadi, subjektif yang dipengaruhi oleh budaya, persepsi seseorang, perhatian dan variabel-variabel psikologis lain yang mengganggu perilaku berkelanjutan dan memotivasi seseorang untuk menghentikan rasa tersebut. Mc Mahon menemukan empat atribut pasti untuk pengalaman nyeri, antara lain: nyeri bersifat individual, tidak menyenangkan, merupakan kekuatan yang mendominasi dan bersifat tidak berkesudahan (Andarmoyo, 2013).

Penelitian ini menggunakan responden ibu post SC hari kedua. Selama operasi SC terjadi perlukaan inisisi di dalam perut dan rahim ibu yang memyebabkan terputusnya inkontinuitas jaringan perut dan rahim. Hal ini mengakibatkan nyeri yang dirasakan oleh ibu. Ibu post SC memang diberikan obat analgesik untuk mengatasi nyeri yang timbul, namun rasa nyeri akan tetap terasa dan bervariasi antara ibu yang satu dengan yang lainnya tergantung dari ambang nyeri yang dimiliki. Apalagi jika tubuh ibu digunakan untuk bergerak atau beraktivitas, maka rasa nyeri akan semakin terasa.

Tabel 1 menunjukkan bahwa responden dengan rentang usia 31-35 tahun sebagian besar mempunyai tingkat nyeri sedang, yaitu sebanyak 10 orang $(55,6 \%)$.

Usia sangat penting dalam mempersepsikan dan mengekspresikan nyeri. Pasien dewasa memiliki respon yang berbeda terhadap nyeri dibanding dengan lansia. Banyak penelitian telah dilakukan untuk mengetahui pengaruh usia terhadap nyeri dan hasilnya sudah tidak konsisten. Washington, Gibson dan Helme (2000) menemukan bahwa orang tua intensitas lebih tinggi daripada orang usia muda.

Rasa nyeri yang dirasakan oleh setiap orang memang berbeda-beda tergantung dari ambang nyeri yang dimiliki. Namun selain itu faktor usia juga bisa digunakan sebagai standar untuk mengukur ambang nyeri seseorang meskipun tidak bisa disamaratakan. Semakin dewasa atau berumur seseorang maka respon terhadap nyeri yang dialami bisa lebih matang.

Tabel 2 menunjukkan bahwa responden dengan paritas multipara sebagian besar mempunyai tingkat nyeri sedang, yaitu sebanyak 14 orang $(56 \%)$. Individu yang mempunyai pengalaman multiple dan berkepanjangan akan lebih sedikit gelisah dan lebih toleran terhadap nyeri dibanding dengan orang yang hanya mengalami sedikit nyeri (Andarmoyo, 2013).

Seseorang yang pernah berhasil mengatasi nyeri dimasa lampau, dan saat ini nyeri yang sama timbul, maka ia akan lebih mudah mengatasi nyerinya. Mudah tidaknya seseorang mengatasi nyeri tergantung pengalaman dimasa lalu dalam mengatasi nyeri. Pengalaman melahirkan masa lalu bisa mempengaruhi ambang nyeri seorang ibu. Ibu primipara yang melahirkan anak pertama akan merasakan nyeri yang lebih sakit daripada ibu multipara. Hal ini bisa dipengaruhi karena kematangan psikologis dan pengalaman nyeri yang pernah diderita ibu multipara saat melahirkan sebelumnya.

\section{Mobilisasi Dini Pada Ibu Post Sectio Caesarea Di Pavilyun Melati RSUD Jombang}

Hasil penelitian menunjukkan bahwa hampir setengah dari responden $(44,1 \%)$ mempunyai mobilisasi dini dengan kategori cukup, yaitu sebanyak 15 orang. Hal ini mungkin dipengaruhi oleh beberapa faktor, antara lain yang tercantum dalam penelitian ini adalah faktor tingkat pendidikan dan riwayat SC sebelumnya.

Mobilisasi pasca Sectio Caesarea adalah suatu pergerakan, posisi, atau adanya 
kegiatan yang dilakukan ibu setelah beberapa jam melahirkan dengan persalinan. Untuk mencegah komplikasi paska operasi ibu harus segera melakukan mobilisasi sesuai dengan tahapnya. Oleh karena setelah mengalami operasi, seorang ibu disarankan tidak malas untuk bergerak pasca operasi sectio caesarea, ibu harus mobilisasi cepat. Semakin cepat bergerak itu semakin baik, namun mobilisasi harus tetap dilakukan secara hati-hati (Wirnata, 2010).

Ibu post SC memiliki luka terbuka di bagian perut dan uterus yang dituntut untuk segera pulih. Salah satu cara untuk mempercepat proses penyembuhan luka SC adalah dengan cara melakukan mobilisasi dini karena mobilisasi dini.

Tabel 3 menunjukkan bahwa responden dengan tingkat pendidikan menengah hampir dari setengahnya mempunyai mobilisasi dini baik yaitu sebanyak 8 orang $(47,1 \%)$. Menurut Perinansia (2008), pendidikan berarti bimbingan yang diberikan oleh seseorang terhadap orang ke arah sesuai cita-cita tertentu, ibu yang mempunyai latar belakang pendidikan yang tinggi cenderung lebih memahami akan pentingnya mobilisasi dini setelah dilakukan operasi SC. Tingkat pendidikan turut menentukan mudah tidaknya seseorang menyerap dan memahami pengetahuan mobilisasi dini yang mereka peroleh. Dari kepentingan keluarga pendidikan itu sendiri sangat diperlukan agar lebih tanggap terhadap adanya perilaku mobilisasi dini dan bisa mengambil tindakan secepatnya (Utami, 2008).

Orang dengan pendidikan yang lebih tinggi akan lebih mudah menyerap informasi yang disampaikan oleh tenaga kesehatan terkait mobilisasi dini jika dibandingkan dengan orang yang memiliki tingkat pendidikan yang lebih rendah. Dengan begitu tingkat kepatuhan dan ketepatan pelaksanaan mobilisasi dini akan semakin tinggi peluangnya dicapai oleh orang dengan pendidikan yang lebih tinggi.

Tabel 4 menunjukkan bahwa sebagian besar $(67,6 \%)$ responden belum pernah menjalani operasi SC sebanyak 23 orang. Secara teoritis pengalaman merupakan faktor yang mempengaruhi proses mobilisasi dini dan kesembuhan luka, karena dengan pengetahuan yang di peroleh dari pengalaman sebelumnya, seperti kepatuhan ibu terhadap nutrisi dan mobilisasi dini akan mempercepat pemulihan pembuluh darah sehingga suplai oksigen dan nutrisi yang dibutuhkan oleh luka akan terpenuhi. Salah satu manfaat yang dapat di ambil dengan melakukan mobilisasi dini post SC adalah mencegah terjadinya thrombosis dan tromboemboli karena mobilisasi dini yang dilakukan dengan baik akan melancarkan sirkulasi darah (Mochtar, 2008).

Ibu yang sudah pernah menjalani SC maka sudah pasti terpapar dengan mobilisasi dini dan bahkan sudah pernah melakukannya, sehingga pada saat operasi SC yang berikutnya ibu hanya mengulangi pengalaman mobilisasi dini yang sudah pernah dilakukann. Dengan begitu seharusnya mobilisasi dini yang dicapai oleh ibu yang pernah menjalani SC bisa lebih baik.

\section{Hubungan Tingkat Nyeri Luka Operasi dengan Mobilisasi Dini pada Ibu Post SC Di Pavilyun Melati RSUD Jombang}

Tabel tabulasi silang antara tingkat nyeri luka operasi dengan mobilisasi dini pada tabel 5 diketahui bahwa sebagian besar responden dengan nyeri sedang mempunyai mobilisasi dini cukup yaitu sebanyak 13 orang $(72,2 \%)$.

Hasil Uji Spearman Rank menunjukkan adanya hubungan antara variabel $X$ (tingkat nyeri luka operasi) dengan $\mathrm{Y}$ (mobilisasi dini). Hal ini didukung dengan nilai $\rho=0,002$ yang berarti lebih kecil dari nilai $\alpha(0,05)$ maka $\mathrm{H} 1$ diterima dan $\mathrm{H} 0$ ditolak. Koefisien korelasi menunjukkan nilai 0,515 yang berarti hubungan tingkat nyeri luka operasi dengan mobilisasi dini pada ibu post Sectio Caesarea di Pavilyun Melati RSUD Jombang mempunyai hubungan dengan interpretasi "tingkat hubungan sedang".

Suatu proses pembedahan setelah operasi atau post operasi akan menimbulkan respon nyeri. Nyeri yang dirasakan ibu post partum dengan SC berasal dari luka yang terdapat dari perut (Kasdu, 2003). Tingkat dan keparahan nyeri pasca operatif tergantung pada fisiologis dan 
psikologis individu dan toleransi yang ditimbulkan nyeri (Smeltzer \& Bare. 2002). Banyak pasien SC yang mengeluh rasa nyeri dibekas jahitan sesar. Keluhan ini sebenarnya wajar karena tubuh mengalami luka dan poses penyembuhannya tidak sempurna. Dampak nyeri yang perlu di tanyakan adalah hal-hal yang spesifik seperti pengaruhnya terhadap pola tidur, pola makan, energi, aktifitas keseharian (Muttaqin, 2008). Nyeri merupakan suatu kondisi tidak nyaman yang disebabkan oleh stimulus tertentu. Nyeri setelah pembedahan merupakan hal yang biasa terjadi pada banyak pasien yang pernah mengalami pembedahan. Yang perlu diwaspadai adalah jika nyeri itu disertai dengan komplikasi setelah pembedahan seperti luka jahitan yang tidak menutup, infeksi pada luka operasi, dan gejala lain yang berhubungan dengan jenis pembedahan (Potter \& Perry, 2006).

Nyeri tersebut akan menimbulkan berbagai masalah, salah satunya masalah mobilisasi dini. Menurut Kiik (2009), mobilisasi dini yang dilakukan secara teratur menyebabkan sirkulasi di daerah insisi menjadi lancar sehingga jaringan insisi yang mengalami cedera akan mendapatkan zat-zat esensial untuk penyembuhan, seperti oksigen, asam amino, vitamin dan mineral. Oleh karena itu, sangat disarankan oleh ibu untuk sesegera mungkin melakukan mobilisasi dini sesuai tahapan prosedur, yaitu setelah 6 jam pertama post SC ibu yang dilakukan tirah baring hendaknya melakukan gerakan lengan tangan, kaki dan tungkai bawah, serta miring kiri maupun kanan. Setelah itu, ibu mulai dapat duduk setelah 8 sampai 12 jam post operasi. Namun dalam kenyataannya pada ibu post Sectio Caesarea (SC) tidak melakukan mobilisasi dini dengan alasan nyeri pada luka jahitan, dan rasa khawatir jika akan lepas jahitannya.

Nyeri luka post SC yang dirasakan ibu memiliki respon dan sensasi yang beragam dan tidak bisa disamakan satu dengan yang lain dan hanya orang tersebut yang dapat menjelaskan atau mengevaluasi rasa nyeri yang dialaminya, ketika ibu mengalami nyeri ibu akan takut untuk melakukan mobilisasi dini. Tingkat nyeri yang bervariasi juga berimbas pada hasil output mobilisasi dini yang beragam pula. Secara logika jika nyeri yang dialami ibu adalah nyeri ringan maka mobilisasi ibu haruslah masuk dalam kategori mobilisasi dini baik atau bahkan sangat baik. Namun di lapangan tidak demikian adanya. Hal ini bisa dipengaruhi oleh beberapa faktor lain yang juga bisa mempengaruhi proses mobilisasi dini antara lain usia, paritas, tingkat pendidikan dan riwayat SC sebelumnya.

Upaya yang bisa dilakukan untuk menekan efek dari nyeri terhadap pelaksanaan mobilisasi dini salah satunya adalah dengan cara penyuluhan dan penjelasan tentang pentingnya mobilisasi sedini mungkin yang diberikan bahkan sebelum ibu menjalani operasi SC. Dengan begitu diharapkan ibu akan mengesampingkan rasa nyeri yang dirasakan dan tetap melakukan mobilisasi dini sesuai dengan tahapan dan waktunya.

\section{KESIMPULAN}

Tingkat nyeri luka operasi pada ibu post Sectio Caesarea di Pavilyun Melati RSUD Jombang, sebagian besar (52,9\%) responden memiliki tingkat nyeri sedang, yaitu sebanyak 18 orang.

Mobilisasi dini pada ibu post Sectio Caesarea di Pavilyun Melati RSUD Jombang, hampir setengah (44,1\%) responden mempunyai mobilisasi dini dengan kategori cukup, yaitu sebanyak 15 orang.

Terdapat hubungan dengan interpretasi sedang antara tingkat nyeri luka operasi dengan mobilisasi dini pada ibu post Sectio Caesarea di Pavilyun Melati RSUD Jombang.

\section{SARAN}

Bagi institusi pendidikan, hendaknya lebih memperbanyak referensi baik buku maupun jurnal mengenai mobilisasi dini pada ibu post $\mathrm{SC}$ di perpustakaan.

Peneliti selanjutnya hendaknya menggunakan hasil penelitian ini sebagai bahan referensi dan pembanding, sehingga peneliti selanjutnya dapat menggunakan variabel atau subjek yang belum pernah diteliti untukmelengkapi kekurangankekurangan penelitian ini. 
Disarankan untuk ibu post SC yang sudah pulang ke rumah dan rawat jalan agar tetap melakukan mobilisasi dini sesuai yang diajarkan petugas kesehatan meskipun masih merasakan nyeri.

Disarankan untuk Pavilyun Melati RSUD Jombang untuk membuat SOP yang berbeda tentang tahapan-tahapan mobilisasi dini.

\section{KEPUSTAKAAN}

Andarmoyo S. 2013. Konsep dan Proses Keperawatan Nyeri. Yogyakarta: ArRuzz Andayani, SRD. 2017. Disertasi Thesis:

Pengembangan Model Asuhan Keperawatan Comfort pada Ibu Post Sectio Caesaria dalam Pelaksanaan IMD di Rumah Sakit. Surabaya: Universitas Airlangga.

Bobak L. 2005. Keperawatan Maternitas. $4^{\text {th }}$ ed.

Jakarta: EGC

Chapman, V. 2006. Asuhan Kebidanan: Persalinan \& Kelahiran. Jakarta: EGC Harnawatiaj. 2008.

Asuhan Keperawatan Sectio Caesaria. [Online]. Diakses pada November 2017.

http:nursingbegin.com/askep.sectiocaesaria.html

Kiik SM. 2009. Early Mobilization Influence to Peristaltic's Recovery Time Intestine on Pasca's Patient Hands Out Abdomen at ICU BPRSUD Labuang Baji Makassar. STIK Maranatha Kupang.

Kozier, Erb, Berman, Snyder. 2010. Buku Ajar Fundamental Keperawatan: Konsep, Proses \& Praktik. Volume 1, Edisi 7. Jakarta: EGC

Mochtar, R. 2008. Sinopsis Obstetri jilid 2. Jakarta : EGC

Potter PA \& AG Perry. 2006. Buku Ajar Fundamental Keperawatan: Konsep, Proses, Dan Praktik, edisi 4, Volume 2. Jakarta: EGC

RSUD Jombang. 2018. Data Pasien SC tahun 2017 di RSUD Jombang. Jombang

Smeltzer SC \& BG Bare. 2002. Buku Ajar

Keperawatan Medikal Bedah.
Suryani. 2010. Gambaran Mobilisasi Dini pada Pasien Pasca Seksio Sesarea DI RSD Dr. Pirngadi Medan. [Online]. Diakses pada Desember 2017.

repository.usu.ac.id/bitstream/1921

8/5/Chapter\%201.pdf

Taylor L, La Mone. 1997. Fundamentals of

nursing: the art and science of nursing care. $3^{\text {th }} E d$.

Lippincott

Philadhelpia:

Utami R. 2008. Inisiasi Menyusu Dini Plus ASI

Eksklusif. Jakarta: Pustaka Bunda

Wati WS. 2015. Hubungan Nyeri Luka Operasi

dengan Mobilisasi Dini pada Ibu Post

SC di Ruang Mawar RSI Jemursari Surabaya. Skripsi. Surabaya: UNUSA

WHO. 2015. WHO Statement on Caesarean Section Rates.

Wirnata. 2010. Belajar Merawat di Bangsal Anak. Jakarta: EGC

Jakarta: EGC 